\title{
Phage Therapy: Promising For H.pylori Infection
}

\section{Qing-Hua Zou* and Wen Wei}

Department of Microbiology, School of Basic Medical Sciences, Peking University Health Science Center, Beijing, China

Helicobacter pylori (H.pylori) is a widely distributed human pathogen with high prevalence in human population. Many researches showed H.pylori infection is closely related with chronic gastritis, ganstric duodenal ulcer, mucosa associated diseases such as lymphoma and gastric cancer [1,2]. It has been classified as the class I carcinogen in 1994 by the World Health Organization and the International Agency for Research on Cancer consensus group [3]. The prevalence in the human population is $50-80 \%$, with an increasing rate of $1-2 \%$ annually. About 12 million new cases emerged every year. H.pylori infection has become an extrusive public problem.

Unlike more common infection, $H$. pylori are sensitive to only a few medications, including PPI, amoxicillin, clarithromycin, metronidazole and so on. Different combinations of these antibiotics such as PPI combined with two antibiotics have been applied to eradicate the bacteria. However, they usually cannot give an acceptable eradication rate and increasing antibiotic resistance is becoming a problem [4]. At the same time upleasant side effects usually generated along with antibiotic therapies. For example, PPI can change the acid environment in the stomach, however the effect varies in different individuals, and it can lead to liver and kidney damage and thus often have poor compliance for patients [5]. Since the effects of antibiotics cannot meet our needs and multidrug-resistant $H$. pylori increases greatly, new therapies for H.pylori is in need.

Phages are reported as the most abundant organisms on earth and are ubiquitous in the nature. Phage therapy uses phages or their products as biological factors to treat or prevent bacterial infectious diseases. As early as 1917, prelimilary research showed phages can be used as therapeutic agents for bacterial disease [6]. Thereafter, a variety of infections including: gastroenteritis, sepsis, suppurative wounds, dermatitis, osteomelitis, emphysemas and pneumonia were cured by phage therapy in humans. In these experiments, the success rates were about 80 to 95 percent and there was no undesirable reaction [7]. Recent studies also showed many antibiotic-resistant infections such as Bacillus anthracis, Staphylococci, Escherichia, Klebsiella and Propionibacterium acnes were successfully treated by phage therapy [8-11]. Phage therapy has the advantages other biological agents do not have, such as high specificity for target bacterium; safe to be utilized clinically; few side effects; the frequency of phage mutation is much higher than that of bacteria, so if a phage-resistant bacterium emerges, the phage responds quickly [12].

In recent years, more and more researchers began to study $H$. pylori phages which may be possible prophylactic and alternative therapeutic treatment. The first $H$. pylori phages was reported by Schimd et al who isolated a $H$. pylori strain which can produce phages in vivo [13]. This phages can lysogenized $H$. pylori strain SchReck 290 rather than virulent to the bacteria. In 1993, Heintschel et al documented the isolation, propagation, lytic cycle, morphology, and genome composition of HP1 phage, recovered from $H$. pylori strain SchReck 290 [14]. In 2008, Vale et al. described the release of phage-like particles by $H$. pylori following UV induction [15]. In 2011, Lehours et al. discovered that temperate phage of the Siphoviridae family was released from $H$. pylori strain B45 following induction[16]; Wan et al. isolated a wild-type virulent phage of $H$. pylori and studied its simulated treatments of gastrointestinal $H$. pylori in vitro [17]. Other studies characterized H. pylori phage 1961P and KHP30 and found they are dissimilar to any previously sequenced phages and should be a new type of phages[18,19]. All these studies bring new opportunity for $H$. pylori phage discoveries and phage therapy.

Considering the great troubles such as low eradication rate and antibiotic resistance in $H$. pylori therapy, lytic and virulent phages to $H$. pylori appears promising in the future. We believe that with more studies on $H$. pylori phages, we can get a better understanding to the treatment of $H$. pylori. Phage therapies will provide a new effective treatment options for $H$. pylori infections.

\section{References}

1. Nervi G, Liatopoulou S, Cavallaro LG, Gnocchi A, Dal-Bo N, et al. (2006) Does Helicobacter pylori infection eradication modify peptic ulcer prevalence? A 10 years' endoscopical survey. World J Gastroenterol 12: 2398-2401.

2. Kamangar F, Qiao YL, Blaser MJ, Sun XD, Katki H, et al. (2007) Helicobacter pylori and oesophageal and gastric cancers in a prospective study in $\mathrm{China} . \mathrm{Br}$ J Cancer 96: 172-176.

3. Uemura N, Okamoto S, Yamamoto S, Matsumura N, Yamaguchi S, et al. (2001) Helicobacter pylori infection and the development of gastric cancer. N Engl J Med 345: 784-789.

4. De Francesco V, Giorgio F, Hassan C, Manes G, Vannella L, et al. (2010) Worldwide H. pylori antibiotic resistance: a systematic review. J Gastrointestin Liver Dis 19: 409-414.

5. Qasim A, O'Morain CA, O'Connor HJ (2009) Helicobacter pylori eradication: role of individual therapy constituents and therapy duration. Fundam Clin Pharmacol 23: 43-52.

6. Shasha SM, Sharon N, Inbar M (2004) [Bacteriophages as antibacterial agents]. Harefuah 143: 121-125, 166.

7. Alisky J, Iczkowski K, Rapoport A, Troitsky N (1998) Bacteriophages show promise as antimicrobial agents. J Infect 36: 5-15.

8. Slopek S, Kucharewicz-Krukowska A, Weber-Dabrowska B, Dabrowski M (1985) Results of bacteriophage treatment of suppurative bacterial infections. V. Evaluation of the results obtained in children. Arch Immunol Ther Exp (Warsz) 33: 241-259.

9. Slopek S, Durlakowa I, Weber-Dabrowska B, Kucharewicz-Krukowska A Dabrowski M, et al. (1983) Results of bacteriophage treatment of suppurative bacterial infections. II. Detailed evaluation of the results. Arch Immunol Ther Exp (Warsz) 31: 293-327.

10. Slopek S, Durlakowa I, Weber-Dabrowska B, Kucharewicz-Krukowska A Dabrowski M, et al. (1983) Results of bacteriophage treatment of suppurative bacterial infections. I. General evaluation of the results. Arch Immunol Ther Exp (Warsz) 31: 267-291.

${ }^{*}$ Corresponding author: Qing-Hua Zou, Department of Microbiology, Peking University Health Science Center, No.38 Xue Yuan Road, Haidian District, Beijing, 100191 ,China , Tel: +861082802807 ; E-mail: zouqinghua@bjmu.edu.cn

Received April 22, 2013; Accepted April 25, 2013; Published April 27, 2013

Citation: Zou QH, Wei W (2013) Phage Therapy: Promising For H.pylori Infection. Clin Microbial 2: 112. doi:10.4172/2327-5073.1000112

Copyright: ( 2013 Zou QH, et al. This is an open-access article distributed under the terms of the Creative Commons Attribution License, which permits unrestricted use, distribution, and reproduction in any medium, provided the original author and source are credited. 
11. Slopek S, Durlakowa I, Weber-Dabrowska B, Dabrowski M, KucharewiczKrukowska A (1984) Results of bacteriophage treatment of suppurative bacterial infections. III. Detailed evaluation of the results obtained in further 150 cases. Arch Immunol Ther Exp (Warsz) 32: 317-335.

12. Sabouri Ghannad M, Mohammadi A (2012) Bacteriophage: time to re-evaluate the potential of phage therapy as a promising agent to control multidrugresistant bacteria. Iran J Basic Med Sci 15: 693-701.

13. Schmid EN, von Recklinghausen G, Ansorg R (1990) Bacteriophages in Helicobacter (Campylobacter) pylori. J Med Microbiol 32: 101-104.

14. Heintschel von Heinegg E, Nalik HP, Schmid EN (1993) Characterisation of a Helicobacter pylori phage (HP1). J Med Microbiol 38: 245-249.

15. van Vliet AH, Wooldridge KG, Ketley JM (1998) Iron-responsive gene regulation in a campylobacter jejuni fur mutant. J Bacteriol 180: 5291-5298.
16. Lehours P, Vale FF, Bjursell MK, Melefors O, Advani R, et al. (2011) Genome sequencing reveals a phage in Helicobacter pylori. MBio 2.

17. Wan XQ, Tang DS, Liu AP, Tan SY, Li WK, et al. (2011) [lsolation of a wildtype virulent phage of Helicobacter pylori and its simulated treatments of gastrointestinal $\mathrm{Hp}$ in vitro]. Nan Fang Yi Ke Da Xue Xue Bao 31: 304-307.

18. Luo CH, Chiou PY, Yang CY, Lin NT (2012) Genome, integration, and transduction of a novel temperate phage of Helicobacter pylori. J Virol 86 8781-8792.

19. Uchiyama J, Takeuchi H, Kato SI, Gamoh K, Takemura-Uchiyama I, et al. (2013) Characterization of Helicobacter pylori bacteriophage KHP30. Appl Environ Microbiol . 